\title{
Colorimetric $\mathrm{CO}$ and $\mathrm{NO}_{2}$ Gas Sensors for Fire Detection
}

\author{
Carolin Peter ${ }^{1}$, Daniel Gutmacher ${ }^{2}$, Ina Schumacher ${ }^{1}$, Katrin Schmitt ${ }^{1}$, Jürgen Wöllenstein ${ }^{1}$ \\ ${ }_{1}^{1}$ Fraunhofer Institute for Physical Measurement Techniques, Heidenhofstr. 8, 79110 Freiburg, \\ Germany \\ Carolin.peter@ipm.fraunhofer.de, \\ ${ }^{2}$ Siemens Schweiz AG, Building Technologies Division, Gubelstr. 22, 6300 Zug, Switzerland
}

\begin{abstract}
:
We present the development of a novel $\mathrm{CO}$ and $\mathrm{NO}_{2}$ sensing principle using gasochromic materials. The sensor set-up works with a very low power consumption to enable their usage in commercial fire detection systems. $\mathrm{CO}$ and $\mathrm{NO}_{2}$ are both typical fire indicating gases. For the detection of $\mathrm{CO}$ we used a binuclear rhodium complex. $\mathrm{NO}_{2}$ can be detected using the chinonime dye $\mathrm{N}, \mathrm{N}, \mathrm{N}^{\prime}, \mathrm{N}^{\prime}$-tetramethylphenylene-diamine. Both dyes were embedded into a highly porous polymer and deposited on planar optical waveguides by spin coating. The capability of the developed sensors was shown in a real fire lab, regarding different standardized test fires.
\end{abstract}

Key words: gas sensor, evanescence field, colorimetric sensor, fire detection

\section{Introduction}

Reliable fire detectors are very import for everyday's life. Most commercial detection devises are so-called scattered light sensors. In case of a fire, the light of a LED gets diverted on fume particles and is focused on a photo detector. This causes the fire alarm. The principle bases on the assumption that all fires produce fume particles. These detectors are low-priced and work for many years, but they have other disadvantages. An alarm can not only be caused by a fire, also by other particle producing events like cooking, hot shower etc. To detect fires with higher probability, it's important to detect typical fire gases like carbon monoxide (CO) and nitrogen dioxide $\left(\mathrm{NO}_{2}\right)$. Both gases are very toxic and shouldn't appear in rooms under normal conditions. Requirements for commercial fire detectors are that they are low-cost and low-power and work with a battery for up to ten years. This is unfortunately not realizable using commercial affordable metal-oxide gas sensors.

In this publication we present an alternative measurement principle to detect $\mathrm{CO}$ and $\mathrm{NO}_{2}$ reversible in fire typical concentrations without interfering sensitivities to other gases.

\section{Experimental}

The improvement is the detection of $\mathrm{CO}$ and $\mathrm{NO}_{2}$ using a colorimetric effect.
As gasochromic material for $\mathrm{CO}$ detection we used a binuclear rhodium complex embedded into a porous ethyl cellulose matrix. The complex has been characterized in [1]. The performance of a congeneric Rh-complex to $\mathrm{CO}$ has been described in [2]. The complex has been synthesized analogue to [1], fig. 1 shows the reaction of the rhodium complex to $\mathrm{CO}$.

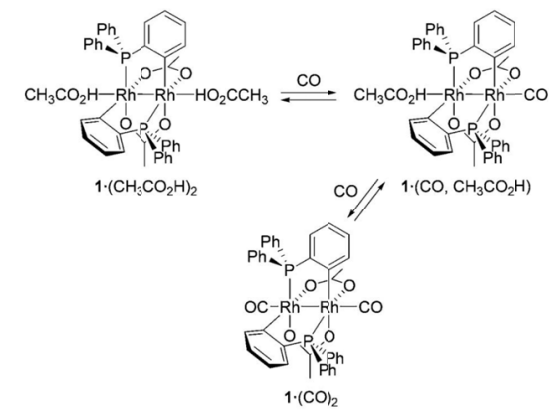

Fig. 1. Reaction of the rhodium complex to CO. This reaction induces a color change from violet to yellow [3].

For $\mathrm{NO}_{2}$ detection we investigated $\mathrm{N}, \mathrm{N}, \mathrm{N}^{\prime}, \mathrm{N}^{\prime}-$ tetramethyl-phenylene-diamine

(TMPD). TMPD, also called Wurster's blue, is a chinonime dye, which was embedded into a polyvinyl chloride (PVC) matrix. Fig. 2 shows the reaction of TMPD (left) to $\mathrm{NO}_{2}$. The centered molecules are two different forms of the radical cation, which is blue. A second oxidation step reacts to the colorless di-cation (right). The equilibrium lies on the side of the blue cation [3]. 
Spectroscopic measurements have been performed with both dyes. The spectra were recorded using a Perkin Elmer Lambda 900 spectrometer. On the basis of the spectra it's possible to determine the region of maximum wavelength shift due to gas exposure.

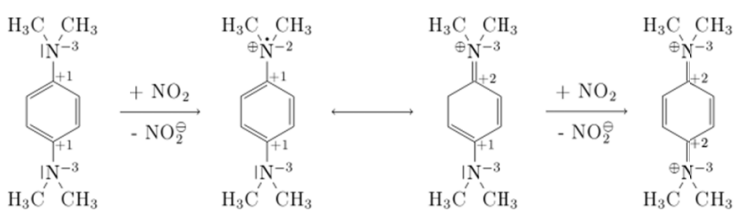

Fig. 2: Reaction of TMPD (Wurster's blue) to $\mathrm{NO}_{2}$. The TMPD (left) gets oxidized to a blue cation. Another oxidation steps generates the colorless dication (right). The equilibrium lies on the first oxidation step (middle).

\section{Laboratory tests}

Fig. 3 shows the transmission spectra of both dyes during gas exposure. The Rh-dye was embedded into an EC-matrix and exposed to 240 ppm CO at $40 \%$ r.H. in ambient air. The exposure leads to an increasing of the maximum transmission at $485 \mathrm{~nm}$, resp. to a decreasing at $560 \mathrm{~nm}$. TMPD was embedded into a PVC -matrix and exposured to $5 \mathrm{ppm}$ $\mathrm{NO}_{2}$ at $40 \%$ r.H. in ambient air. The gas generates three new minimums at $456 \mathrm{~nm}, 568$ $\mathrm{nm}$ and $622 \mathrm{~nm}$.
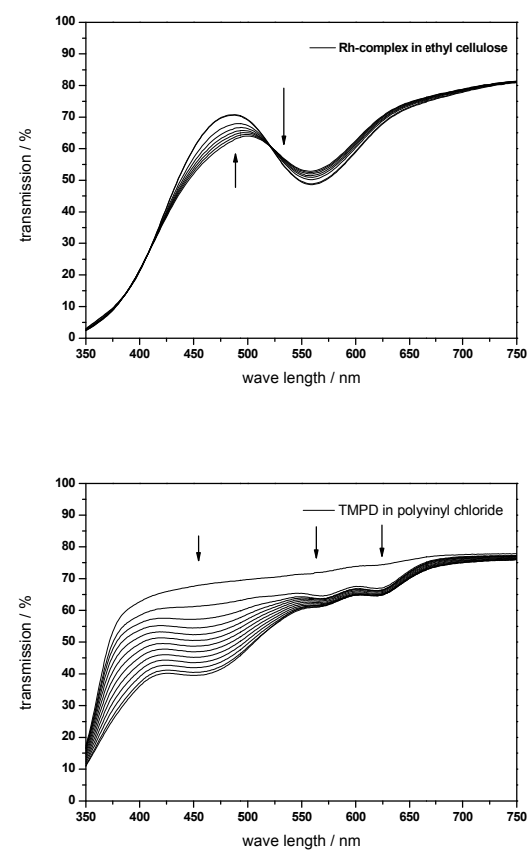

Fig. 3. Above: transmission spectra of Rh complex to $240 \mathrm{ppm} \mathrm{CO}$ at $40 \% \mathrm{r}$.H. in ambient air. Down: reaction of TMPD to $5 \mathrm{ppm} \mathrm{NO2} \mathrm{at} 40 \%$ r.H. in ambient air.

\section{Sensing principle}

The sensors work after a colorimetric principle. Thereby, the color of a dye changes due to gas exposure. This principle is widely used in so-

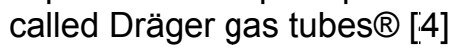

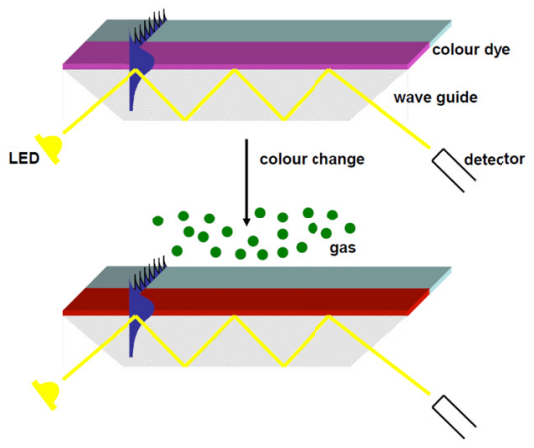

Fig. 4: Sketch of the microscope slide. The lower half is covered with the gasochromic dye. The light of an LED is coupled into one end of the waveguide and travels trough it under TIR before it is focused onto a photo detector. Changes in the color of the dye, due to a gas reaction can be detected by changes in the out-coupled light.

But, in comparison to these gas tubes, a sensor has to work independently without the assistance of an operator. Our measurement principle bases on changes in the evanescence field of the dye. To detect this, the dye gets deposited on planar optical waveguides. The used sensing principle has been already described in detail in [5]. A sketch of the colorimetric sensing principle is shown in fig. 4 ; fig. 5 shows the realized sensor with integrated electronic for signal procesising.

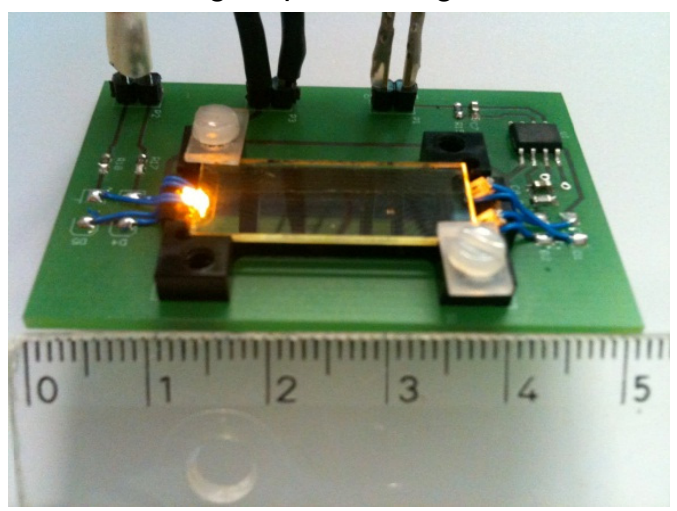

Fig. 5: Photograph of the developed sensor setup. The implemented sensor is deposited with the TMPD dye. The usage of SMD electronics minimizes the set-up tremendiously.

It was our aim to use only sensor for both gases. The transmission spectra show, that the highest shift in transmission is in the area about $460 \mathrm{~nm}$. Due to this fact we integrated a blue LED $\left(\lambda_{\max }=470 \mathrm{~nm}\right)$ in the system. 


\section{Real fire tests}

With the developed sensor set-up real fire gas measurements were performed. The test fires were carried out in a $240 \mathrm{~m}^{3}$ fire lab, analogue to the standardized test fires in EN 54. These test fires differ in their fire material and in consequence in their gas composition. We regarded the two test fires TF 2 and TF 6 . TF 2 is a wood based smoldering fire with low heat development, but smoke emission. Compared to this, TF 6 is an ethanol liquid fire with strong heat development but without any smoke emission. TF 6 is a perfect example of the need of gas based fire detectors [6]. The results of these test fires to the colorimetric sensors are shown in fig. 6 resp. fig. 7 .

The dyes were spin coated for $20 \mathrm{sec}$. with 2000 RPM on $1 \times 3.8 \mathrm{~cm}^{2}$ big optical wave guides. The dyes had a resulting thickness of 1 $\mu \mathrm{m}$ for TMPD, resp. $1.6 \mu \mathrm{m}$ for the Rh-complex.

Fig. 6 shows the reaction of the Rh-complex to TF 2. During the test, beech wood was heated up, till it started to smolder. After $37.3 \mathrm{~min}$ the CO concentration reaches $86 \mathrm{ppm}$. The colorimetric sensor changes his output signal about $18 \mathrm{mV}$ from $271 \mathrm{mV}$ to $253 \mathrm{mV}$. After ventilation the sensor needs $4.7 \mathrm{~min}$ to reach again its $\mathrm{T}_{90}$ value. The actual $\mathrm{CO}$ concentration was recorded with a Binos 100 [7] gas analyzer.

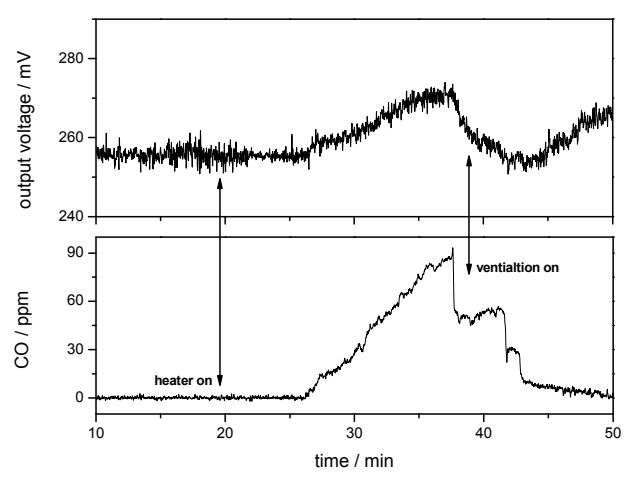

Fig. 6. Reaction of the Rh-dye to TF2. The output signal of the colorimetric sensor is analogue to the reference $\mathrm{CO}$ sensor.

The TMPD dye was exposed to TF 6 . According to EN 54, the $\mathrm{NO}_{2}$ concentration can reach up to $2 \mathrm{ppm}$. The recorded measurement is shown in fig. 7. For fire generating, 2.53 liters ethanol were inflamed. After burning for 10 minutes the following gas concentrations are detectable: $\mathrm{CO}$ : $4.68 \mathrm{ppm}$; $\mathrm{CO}_{2}: 8110 \mathrm{ppm}$; NO: $1785 \mathrm{ppb}$ and $\mathrm{NO}_{2}: 695 \mathrm{ppb}$. The output voltage of the colorimetric sensor decreases from 503 $\mathrm{mV}$ to $158 \mathrm{mV}$ during $\mathrm{NO}_{2}$ exposure. This is a signal change of $69 \%$. After 10 minutes the fire was extinguished and the room was ventilated. After 24 minutes the sensor reaches his $T_{90}$ value again.

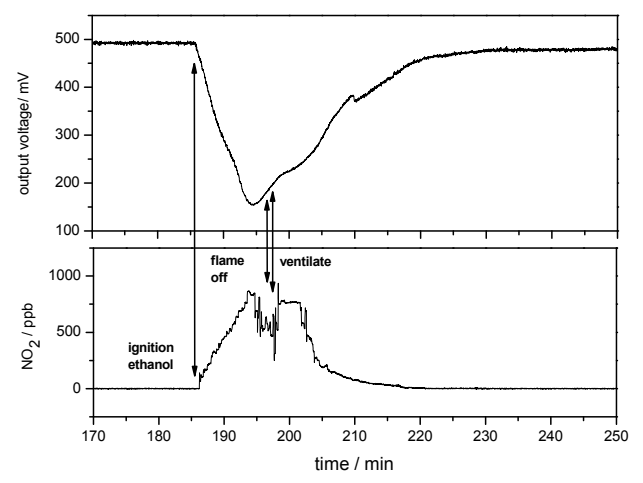

Fig. 7. Reaction of TMPD to TF6. The output signal of the colorimetric sensor is analogue to the reference $\mathrm{NO}_{2}$ sensor.

\section{Conclusion}

We presented the development of colorimetric gas sensor; especially regarding two different dyes to detect the fire indicating gases $\mathrm{CO}$, resp. $\mathrm{NO}_{2}$. Both dyes were embedded into polymer matrices and deposited on optical waveguides by spin coating. UV/VIS measurements showed the color change of both materials in the blue wavelength area. A demonstrator was built up, to perform real fire tests. The sensors were exposed to the two standardized test fires TF 2 and TF 6 . Both dyes show an excellent gas depending behavior. The measured sensitivities are 0.2 $\mathrm{mV} / \mathrm{ppm}(\mathrm{CO})$ for $\mathrm{Rh}$, resp. $494 \mathrm{mV} / \mathrm{ppm}\left(\mathrm{NO}_{2}\right)$ for TMPD.

We have shown, that these colorimetric sensors a promising alternative to commercial low-cost gas sensors for reliable fire detection.

\section{Acknowledgements}

The authors like to thank the Fraunhofer Gesellschaft for funding within an internal program.

\section{References}

[1] J. Esteban, J. Ros-Lis, R. Martinez-Mánez, Sensitive and Selective Chromogenic Sensing of Carbon Monoxide by Using Binuclear Rhodium Complexes, Angewandte Chemie, 122, 50545057 (2010); doi: 10.1002/anie.201001344

[2] J. Courbat, M. Pascu, D. Gutmacher, D. Briand, J. Wöllenstein, U. Hoefer, K. Severin, NF de Rooij, A colorimetric $\mathrm{CO}$ sensor for fire detection, Procedia Engineering, 25 Eurosensors XXV, 
1329-1332 (2011); doi:

10.1016/j.proeng.2011.12.328

[3] U. Nickel, Des Experiment: Reaktionen mit Wursterschen Kationen, Chemie in unserer Zeit, 12, 89-98 (1978); doi: 10.1002/ciuz.19780120305

[4] www.draeger.com, available 13.01.2012

[5] J. Courbat, D. Briand, J. Damon-Lacoste, J. Wöllenstein, NF de Rooij, Evaluation of $\mathrm{pH}$ indicator-based colorimetric films for ammonia detection using optical waveguides, Sensors and Actuators B, 143, 62-70 (2009); doi:

10.1016/j.snb.2009.08.049

[6] www.bma-

sachverstaendiger.de/index.php?sub=4, available 08.08.2011

[7] www.mbe.ch/downloads/produkte_binos100.pdf, available 21.03.2012 